\title{
Performance comparison of a doubly-salient motor with multi-V-shape ferrite magnets
}

Paul Akiki ${ }^{1,2}$, Maya Hage Hassan ${ }^{1}$, Jean-Claude Vannier $^{1}$, Mohamed Bensetti ${ }^{1}$, Benjamin Dagusé ${ }^{2}$, Mike McClelland ${ }^{2}$

${ }^{1}$ GeePs I Group of electrical engineering-Paris, UMR CNRS 8507, CentraleSupélec, Univ.Paris-Sud, Université Paris-Saclay,

Sorbonne Universités, UPMC Univ Paris 06

3 \& 11 rue Joliot-Curie, Plateau de Moulon

91192 Gif-sur-Yvette, France.

\begin{abstract}
This paper presents the analysis of a novel doubly salient structure with concentrated tooth winding and multi-V shape ferrite magnets. Permanent Magnet Synchronous Machines (PMSM) have been universally used with rare-earth magnets or with ferrite magnets and distributed winding. The proposed topology is presented as an improvement to PMSM for high torque and low-speed applications. It has low copper losses due to its short end-winding and benefits from a low cost by virtue of its lack of rare earth materials. This paper presents two slot/pole combinations: the $18 / 16$ and the 12/10. A 2D Finite Element Analysis is used to investigate the average torque, the power factor and the torque ripple of each structure. It is shown that high performance is achieved for both motors. However, a parametric- analysis is performed on the $18 / 16$ motor and shows that the saliency torque cannot be improved without reducing the torque and the power factor. As for the 12/10 motor, its main drawback is its high torque ripple. The torque ripple is reduced using two techniques; a rotor step skew and the use of an asymmetric pole shape. In this paper, a combination of both methods is proposed in order to reduce specific torque harmonics. Finally a comparison of the two motors is presented in order to determine which one is more suitable for the high torque and low speed application.
\end{abstract}

Keywords-Concentrated winding, multi-V ferrite magnets, torque ripple, Asymmetric poles, Design of Experiments, slot/pole combinations

\section{INTRODUCTION}

Research and development of high torque motors in direct drive applications gained significant attention recently, especially in the field of machine-tools, conveyers, elevators, etc. Generally, such applications operate at low rotational speeds. The conventional drive system, which consists of using a high-speed motor with a mechanical speed reducer, has many drawbacks especially the additional mechanical losses caused by the speed reducer and its low reliability. Hence, the production of high torque at low speed in a direct drive configuration is becoming a challenge for the machine designers and researchers. Such a system would be more reliable and efficient than the classical one. Rare-earth magnets such as Neodymium-Iron-Boron $(\mathrm{NdFeB})$ or Samarium-Cobalt (SmCo) are generally used. These magnets are capable of producing strong magnetic fields and are suitable for synchronous machines in high torque density applications.

The design of Permanent Magnet Synchronous Motors (PMSM) with high torque density is actively studied. Researchers investigated many topologies and different operating principles. In order to improve the torque, the double air-gap structure has been widely studied. Motors with 2 stators and 1 rotor with distributed winding [1] or concentrated winding [2], [3] are able to produce a high torque but the manufacturing process of such designs is very complicated.

\author{
${ }^{2}$ Leroy Somer Motors \\ Boulevard Marcellin Leroy \\ 16000 Angoulême, France
}

Another approach to improve the torque is to increase the surface of the air-gap; this is done using an exterior rotor [4][6]. A more novel operating principle emerged lately, known as flux switching. The magnets are on the stator side and the rotor is a passive magnetic circuit with poles similar to the one used in switched reluctance motors [7]-[9]. When the magnets are placed on the stator, their temperature rise may be more easily managed and the risk of demagnetization is reduced [10]. Hybrid excitation flux switching machines were also studied [11]-[14]. The extra excitation winding offers a variable flux capability, but it makes the structure more complex and requires an additional inverter to supply the excitation coil.

The previously mentioned structures are mainly based on rare-earth magnets. However, the rising price of these magnets has led to an increase in the cost of the motor. In order to solve this problem, a variety of motors which do not use or with reduced rare-earth materials have been extensively developed for high torque density applications. An external rotor switched reluctance motor is presented in [15] but is reported to have issues with noise and vibration. The authors in [16] used Vshape magnets in the rotor in order to concentrate the flux and minimize the volume of the magnets. Another category of motors is the one that uses non rare-earth permanent magnets such as ferrite or alnico. The low magnetic field created by these type of magnets forces the designers to use them in a flux concentration configuration [17] or to use them as an additional torque component in synchronous reluctance motors. This machine is called Permanent Magnet Assisted Synchronous Reluctance Motor (PMASynRM) with distributed stator winding [18], [19].

In this paper, a novel electric machine design has been investigated. It is a doubly-salient structure with a concentrated tooth winding on the stator and multi- $\mathrm{V}$ shape ferrite magnets in the rotor. The main advantages of this structure are the high torque that can be achieved and the low Joule losses in the winding. In fact, the multi-V-shape configuration enhances the flux concentration phenomenon compared to the simple Vshape magnet, and the short end-coil of the concentrated tooth winding offers the possibility of reducing the copper losses which can increase the efficiency of the machine. This type of motor is shown to be a good candidate for high torque applications. However, there are very few technical papers that investigated the performance of these motors [20]. Hence, a comprehensive comparison and analysis of multi- $\mathrm{V}$-shape magnet with concentrated tooth winding motors is necessary.

When designing motors for direct drive applications, two essential criteria have to be met: the first one is the ability to develop high torque at low speed and the second one is the smoothness of the torque produced. The slot/pole combination is a key parameter that affects the above mentioned criteria. Two different combinations will be studied in this paper: the $18 / 16$ and the $12 / 10$ motors. Thus, in the next two sections, 2D 
Finite Element Analysis (FEA) using FEMM coupled with MATLAB is conducted to evaluate the performances of the two structures in terms of electromagnetic torque, power factor and torque ripple. The results of an FEA simulation for each topology are presented and an analysis based on certain geometrical parameters is conducted in order to better understand how the drawbacks of each machine can be improved. Finally, a comparison of the two machines performance is given in order to determine which one is more suitable for the high torque and low speed application.

\section{ANALYSIS OF THE 18/16 STRUCTURE}

The structure with 9 stator slots and 8 rotor poles is often encountered since it develops a very smooth torque due to the fact that 9 and 8 have no common divider [21]. However, a rotating force acts on the stator because of the harmonic nature of this structure. This leads to the recommendation to only use multiples of this combination, in order to provide harmonic cancellation [21]. The first multiple of this elementary structure, for instance, the 18/16 structure is considered in this paper. This section presents the winding sequence of the stator. Then a reference machine is considered and its performance is shown. Next, the analysis of the saliency torque and the total torque is made. Finally, the torque ripple of the structure is presented.

\section{A. Winding Configuration for the 18/16 Motor}

The machine is a three phase motor $(m=3)$, and is designed with a non-overlapping concentrated tooth winding. A double layer winding is chosen so that the fundamental winding factor for the 18 slot/16 pole design is high and equal to 0.945 which makes this topology suitable for high torque production [21]. Each tooth has a concentrated coil and the mechanical angle between two consecutive coil-vectors is $20^{\circ}$. The complete vector diagram of the stator is given in Fig.1 with tooth number 1 arbitrarily set at zero angle. In order to determine the proper winding for each coil, the mechanical angles $\left(\theta_{\text {meca }}\right)$ are converted to electrical angles $\left(\theta_{\text {elec }}\right)$ by using the following equation:

$$
\theta_{\text {elec }}=p \theta_{\text {meca }}
$$

where $p=8$ (number of pole pairs). The electrical angle is then matched with the closest relevant angle of a normal 3 phase vector diagram (Fig.2). If the first coil is $\mathrm{A}+$, the second one is at 160 electrical degrees so it is matched with 180 electrical degrees which corresponds to A-. This procedure is applied for every single tooth and leads to the following winding sequence: $\mathrm{A}+\mathrm{A}-\mathrm{A}+, \mathrm{B}+\mathrm{B}-\mathrm{B}+, \mathrm{C}+\mathrm{C}-\mathrm{C}+$. This winding pattern is repeated twice in order to cover the whole stator.

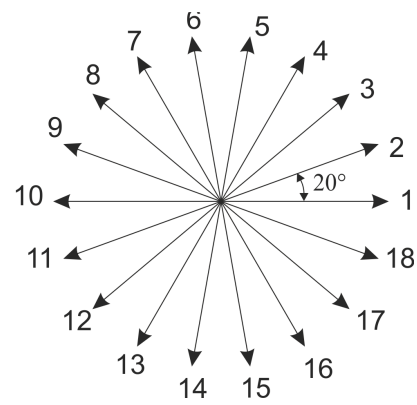

Fig.1. Vector diagram of the stator with 18 slots

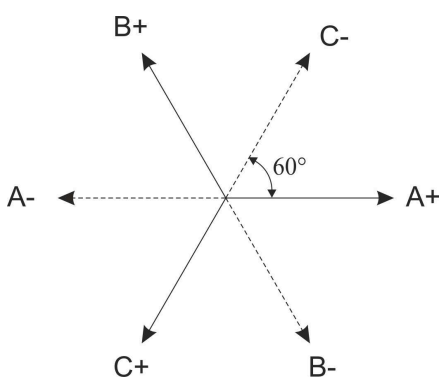

Fig.2. Vector diagram of a 3 phase system

\section{B. Motor Structure Investigation}

The considered machine presents 2 layers of $\mathrm{V}$-shape permanent magnets (PM) as shown in Fig.3. A layer (or barrier) is mainly defined by 2 parameters presented in Fig.4: $\delta$ is the barrier's tilt angle and $k=\theta / \beta$ is the ratio of the barrier's opening angle with respect to the half pole angle. Since each pole has 2 barriers, the index $i$ is added to the parameter $k$ in order to designate the barrier number 1 or 2 . All poles are symmetrical so the same $\delta$ and $k_{i}$ values are applied to all of them. A reference machine is considered such that $\delta=5^{\circ}, k_{1}=$ 0.6 and $k_{2}=0.3$. The specifications for the FEA of this structure are given in TABLE I.

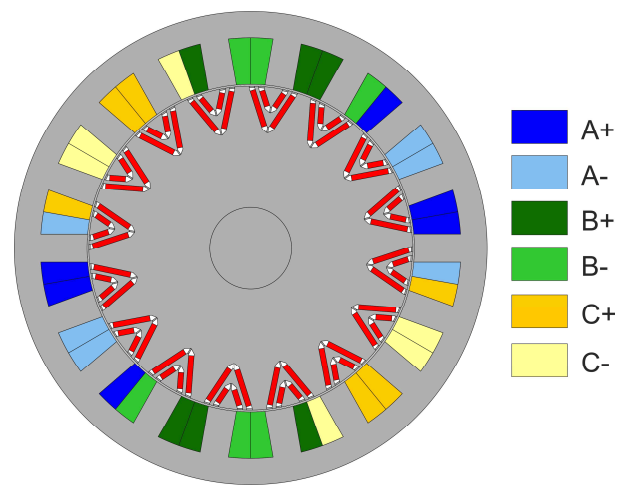

Fig.3. 18/16 motor structure

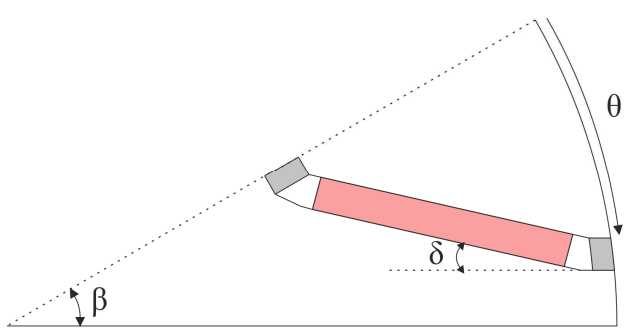

Fig.4. Layer geometrical parameters

TABLE I. SPECIFICATIONS OF THE 18/16 REFERENCE MACHINE

\begin{tabular}{|c|c|}
\hline Specification & Value \\
\hline Stack length & $200 \mathrm{~mm}$ \\
\hline Exterior diameter & $260 \mathrm{~mm}$ \\
\hline PM remanent flux density & $0.4 \mathrm{~T}$ \\
\hline Target average torque & $190 \mathrm{Nm}$ \\
\hline Target torque ripple & $5 \%$ \\
\hline Rated speed & $500 \mathrm{rpm}$ \\
\hline Rated current & $40 \mathrm{~A}(\mathrm{rms})$ \\
\hline$\delta$ & $5^{\circ}$ \\
\hline$k_{1}$ & 0.6 \\
\hline$k_{2}$ & 0.3 \\
\hline
\end{tabular}

Fig.5 shows the mean torque versus the current angle $\alpha$ (angle between the current vector and the q-axis) in electrical degrees $\left({ }^{\circ} \mathrm{elec}\right)$. The maximum torque is obtained for $\alpha=$ $20^{\circ}$ elec which implies that the d-component of the current (Id) is very small compared to its q-component $(I q)$.In fact, the mean torque is given by the following equation:

$$
T=\frac{3 p}{2}[\underbrace{\psi_{P M} I_{q}}_{\text {PM torque }}+\underbrace{\left(L_{d}-L_{q}\right) I_{d} I_{q}}_{\text {Saliency torque }}]
$$

where $\psi_{P M}$ is the permanent magnet flux , $L_{d}$ and $L_{q}$ are the inductance in the $d$ and $q$ axis respectively. Thus, the maximum torque is achieved with $I_{d} \ll I_{q}$ when $\left(L_{d}-L_{q}\right)$ is small which means that this machine presents a low saliency ratio $\left(L_{d} / L_{q}\right)$. With this knowledge, the current angle value at optimal torque $\left(\alpha_{o p t}\right)$ represents the saliency of the structure: a high value of $\alpha_{\text {opt }}$ reflects a high saliency ratio and vice versa. Since the salient component of the torque is magnet-free, it is 
important to maximize the saliency ratio so that the same torque value is obtained with less magnet volume which reduces the motor's cost. The objective of the next paragraphs is to analyze the effect of barrier number and tilt angle on the torque and the power factor of the machine.

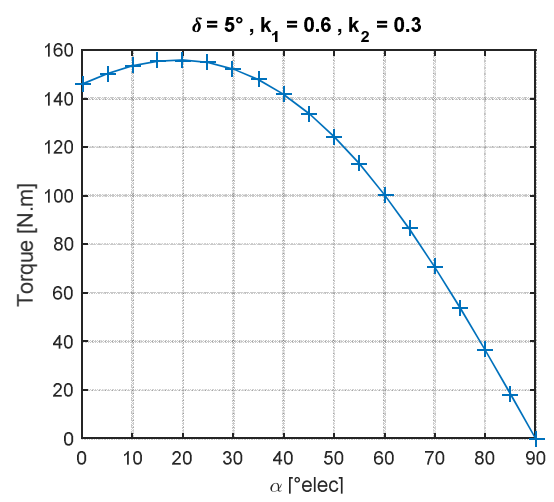

Fig.5. Torque vs current angle for the 18/16 reference machine

\section{Saliency Torque Investigation}

To better understand the salient component of the torque, the magnets are deliberately omitted. At this point, the structure becomes a synchronous reluctance motor. The torque is produced by the difference between $L_{d}$ and $L_{q}$. A parametric FEA analysis is conducted. Fig. 6 represents the saliency torque with respect to the current angle for different values of $\delta$ from 0 to $15^{\circ}$. It shows that the optimal torque is obtained at $\alpha=$ $45^{\circ} \mathrm{elec}$ and that its value increases with the barrier tilt angle. Its maximum is found to be equal to $32 \mathrm{Nm}$. Fig. 7 shows the effect of the number of barriers on the saliency torque. The maximum torque increases significantly from 1 to 2 barriers, as would be expected since the field lines encounter a lower reluctance in the q-axis than in the d-axis, so the difference between $L_{d}$ and $L_{q}$ increases. However, a 3 barrier structure doesn't significantly improve the saliency torque. This is due to the limited geometrical space as a result of the high number of poles (16 poles). Thus, a two barrier structure is retained for further investigation.

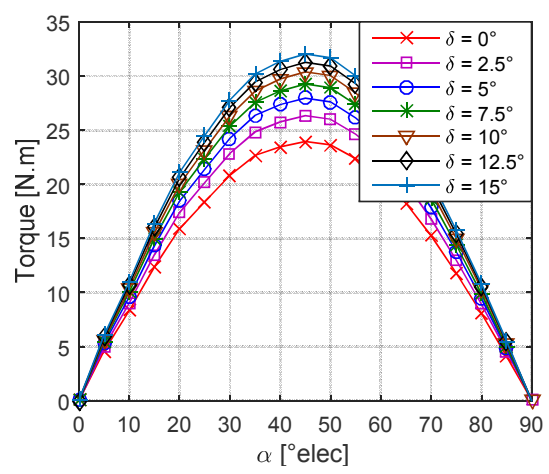

Fig.6. Saliency torque (without PM) for different values of $\delta$

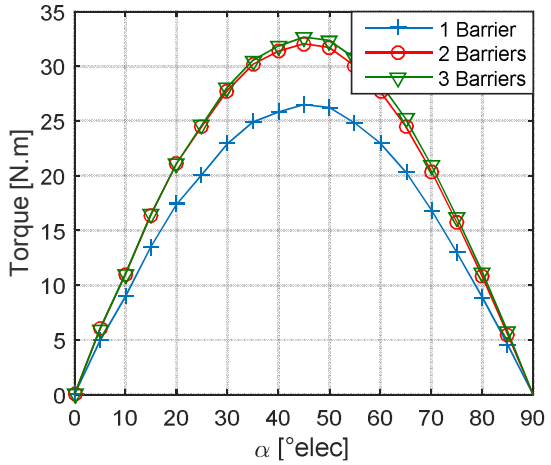

Fig.7. Saliency torque (without PM) for different numbers of barriers

\section{Total Torque and Power Factor Analysis}

The presence of PM in the flux barriers affects the torque and the Power Factor (PF) of the machine. The 2 barrier structure is considered with $k_{1}$ and $k_{2}$ defined as in TABLE I.

At first, a parametric FEA is conducted with constant PM volume and different values of $\delta$. The results of the simulation are given in Fig.8 for the mean torque and in Fig.9 for the power factor. The optimal torque increases when the value of $\delta$ is higher, with practically a constant optimal current angle $\alpha_{o p t}$ $=30^{\circ}$ elec. The maximum torque is $116 \mathrm{Nm}$. As for the PF, it is higher when $\delta$ is increased knowing that the PM volume remains constant. Therefore, the PF is improved when the ratio of the PM volume to the total barrier volume is high.

In a second phase, the PM volume is not kept constant and it completely fills the barriers for each value of $\delta$ (PM volume $=$ barrier volume). Fig. 10 and Fig.11 show that the optimal torque and the PF can achieve high values when $\delta$ is decreased (idem when PM volume is increased). However, $\alpha_{\text {opt }}$ decreases when $\delta$ becomes smaller. Thus, the salient torque becomes negligible when compared to the PM torque if $\delta$ is decreased.

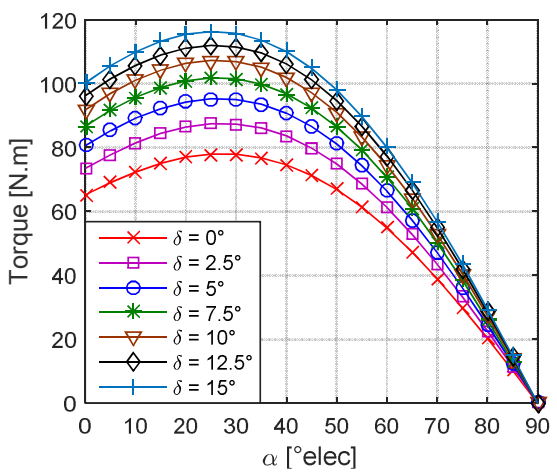

Fig.8. Torque for different values of $\delta$ with a constant PM volume

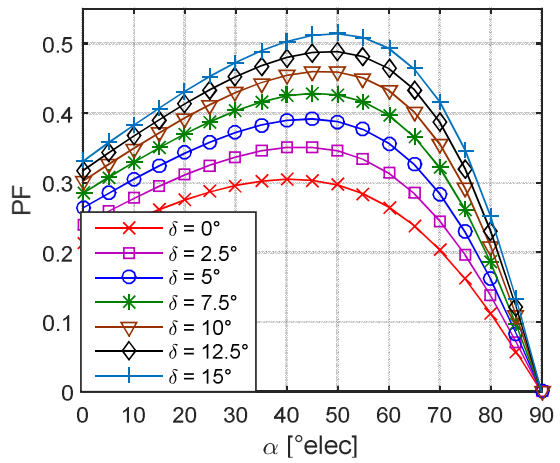

Fig.9. PF for different values of $\delta$ with a constant PM volume

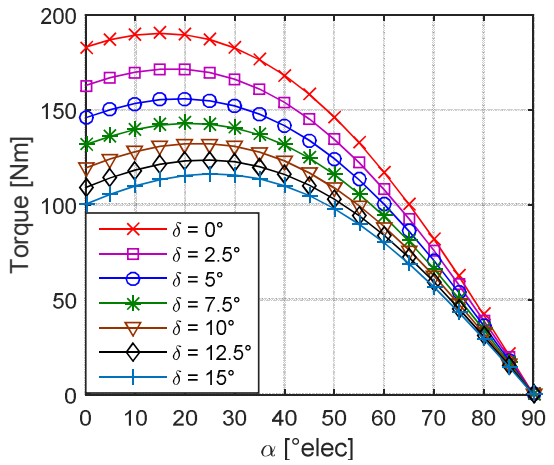

Fig.10. Torque for different values of $\delta$ the barriers completely filled with PM 


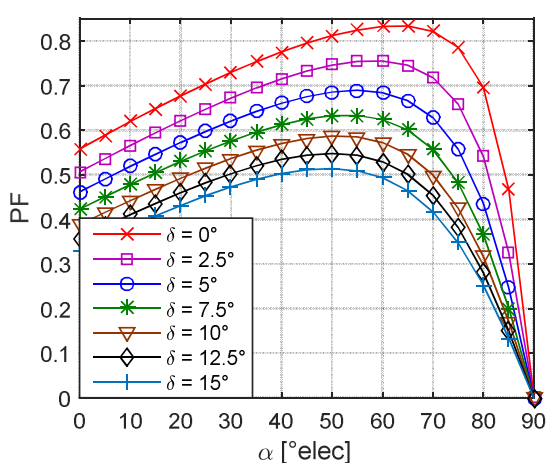

Fig.11. PF for different values of $\delta$ with PM filling at $100 \%$ the barriers

\section{E. Torque Quality Verification}

The torque of the reference machine (TABLE I) is computed for a whole electrical period as shown in Fig.12. The current angle $\alpha=\alpha_{\text {opt }}=20^{\circ}$ elec so the optimal torque is obtained. The torque ripple $(\Delta \mathrm{T})$ is calculated as follows:

$$
\Delta T=\frac{T \max -T \min }{\operatorname{Tavg}}=\frac{T p p}{T a v g}
$$

where $T_{p p}$ is the peak-to-peak torque and $T_{a v g}$ is the average torque. $\Delta T$ is found to be equal to $3.21 \%$ which confirms that the $18 / 16$ structure develops a smooth torque.

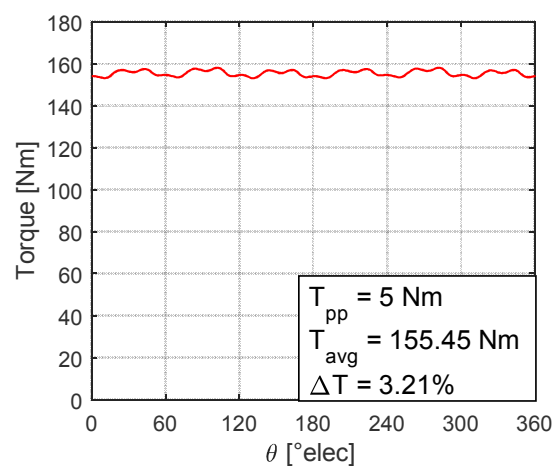

Fig.12. Torque ripple of the reference machine

\section{F. Conclusion for the 18/16 structure}

The average torque, the Power Factor (PF) and the torque ripple of the 18/16 motor are investigated. The analysis of the results shows that this configuration produces a high torque at low rotational speeds with a reasonable PF. Also, the torque ripple is very low. However, a compromise has to be found if one seeks to maximize the saliency torque. In fact, increasing the barrier tilt angle $\delta$ improves the saliency torque but deteriorates the total torque and the PF.

Another quite common slot/pole combination is analyzed in the next section. It is the $12 / 10$ structure. Since the greatest common divisor of the number of slots and the number of poles is equal to 2 , then this configuration results in low unbalanced magnetic force and in low noise [22].

\section{ANALYSIS OF THE 12/10 STRUCTURE}

In this section, the winding of the $12 / 10$ structure is presented. Then, the performance of a reference machine is described. Next, the rotor skewing technique for torque ripple reduction is presented. This is followed by a Design of Experiments (DOE) which is carried out in order to investigate the asymmetric poles technique for torque ripple minimization. Finally, two particular strategies for combining these two methods are studied and an efficient method for torque ripple reduction is proposed. The following paragraphs are a preliminary study that analyzes the electromagnetic torque of the structure.

\section{A. Winding Configuration for the 12/10 Motor}

For the 12/10 structure, as for the 18/16 structure, the double layer non-overlapping concentrated tooth winding is chosen. The fundamental winding factor is equal to 0.933 so the structure would be suitable for high torque production [21]. The machine is a 3 phase motor, and the mechanical angle between two consecutive coil-vectors is $30^{\circ}$. Electrical angles are given by Eq. 1 where $\mathrm{p}=5$. Using the same procedure described for the $18 / 16$ motor, the winding sequence of the 12/10 structure is: A+ A- , B- B+, C+ C- , A- A+ , B+ B- , C$\mathrm{C}+$. It is worth noting that the second half of the stator is acyclic compared to the first one, because one machine half contains an odd number of poles.

\section{B. Performance of the Proposed Structure}

The proposed motor has a rotor with 2 barriers as presented in Fig.13. The layer geometrical parameters are showed in Fig.4. A reference machine is defined with the parameters given in TABLE II.

TABLE II. SPECIFICATIONS OF THE 12/10 REFERENCE MACHINE

\begin{tabular}{|c|c|}
\hline Specification & Value \\
\hline Stack length & $200 \mathrm{~mm}$ \\
\hline Exterior diameter & $260 \mathrm{~mm}$ \\
\hline PM remanent flux density & $0.4 \mathrm{~T}$ \\
\hline Target average torque & $190 \mathrm{Nm}$ \\
\hline Target torque ripple & $5 \%$ \\
\hline Rated speed & $500 \mathrm{rpm}$ \\
\hline Rated current & $40 \mathrm{~A}(\mathrm{rms})$ \\
\hline$\delta$ & $3^{\circ}$ \\
\hline$k_{1}$ & 0.6 \\
\hline$k_{2}$ & 0.3 \\
\hline
\end{tabular}

The results of the FEA for the mean torque with respect to the current angle are shown in Fig. 14. The maximum torque is $200 \mathrm{Nm}$ with $\alpha_{\text {opt }}=30^{\circ} \mathrm{elec}$. The power factor of this machine is given in Fig. 15, it is equal to 0.66 for $\alpha=30^{\circ}$ elec. For the $12 / 10$ combination, the torque is periodic with a period of $60^{\circ} \mathrm{elec}$ which is equivalent to one sixth of an electric period. The torque ripple is shown in Fig. 16. It is calculated using Eq. 3 and is equal to $33 \%$. Therefore, a $12 / 10$ motor is capable of producing a high torque at low speed with a reasonable power factor, but the main drawback of such structure is the torque ripple that is very high. A harmonic decomposition of the torque is presented in Fig. 17. The second $\left(2^{\text {nd }}\right)$ harmonic is the highest one; followed by the first $\left(1^{\text {st }}\right)$ harmonic.

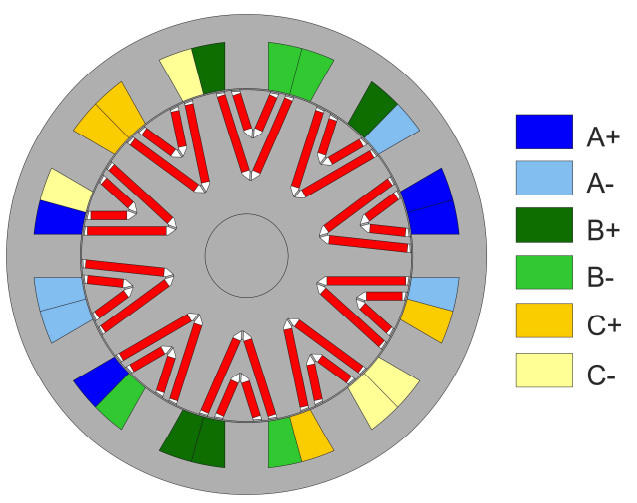

Fig.13. 12/10 motor structure 


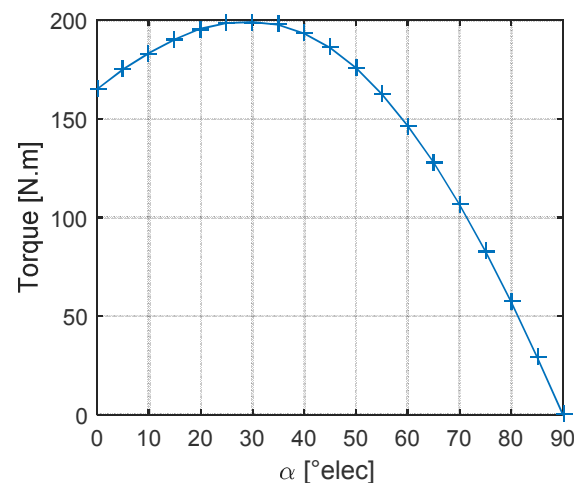

Fig. 14. Torque vs current angle for the $12 / 10$ reference machine

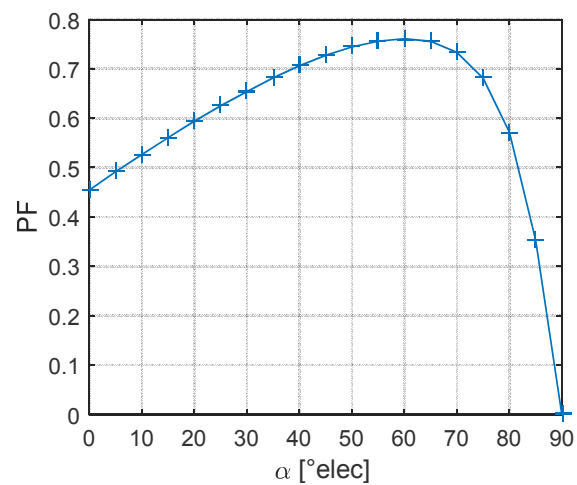

Fig. 15. PF vs current angle for the 12/10 reference machine

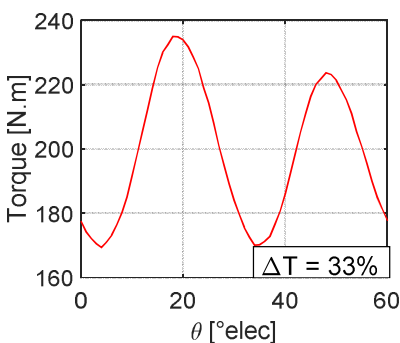

Fig. 16. Torque ripple of the $12 / 10$ reference machine

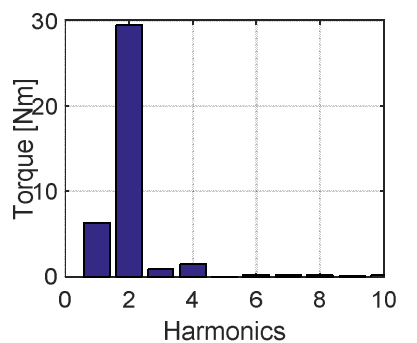
$12 / 10$ reference machine
Fig. 17. Torque harmonics of the

The objective of the next paragraphs is to reduce the torque ripple to less than 5\%. Different techniques for minimizing the torque ripple fall typically into two major categories: the first concerns the machine design and the second is based on active control schemes [23]. In this article, the first category is investigated. Two main techniques can be identified: rotor skewing and rotor magnetic design optimization. Skewing technique was studied during the last decade [24] and it continued to be the subject of recent work with different motor types [25]-[27].As for the magnetic design of the rotor, it includes primarily the design of asymmetric rotor poles [28][30].

\section{Rotor Step Skewing}

Since the $2^{\text {nd }}$ harmonic is the highest one, the skew angle $\left(\psi_{\text {skew }}\right)$ is calculated in order to minimize it. The reduction of the $2^{\text {nd }}$ harmonic is achieved by shifting its phase by $180^{\circ} \mathrm{elec}$. Because it has a period of $30^{\circ} \mathrm{elec}$ the skew angle will be:

$$
\psi_{\text {skew }}=30 \frac{180}{360}=15^{\circ} \text { elec }
$$

which corresponds to 3 mechanical degrees (Eq. 1 with $p=5$ ). Fig. 18 shows the initial torque and the torque with the step skew applied. The total torque is obtained by adding the two waveforms such that $\Delta T$ is reduced from $33 \%$ to $5 \%$.

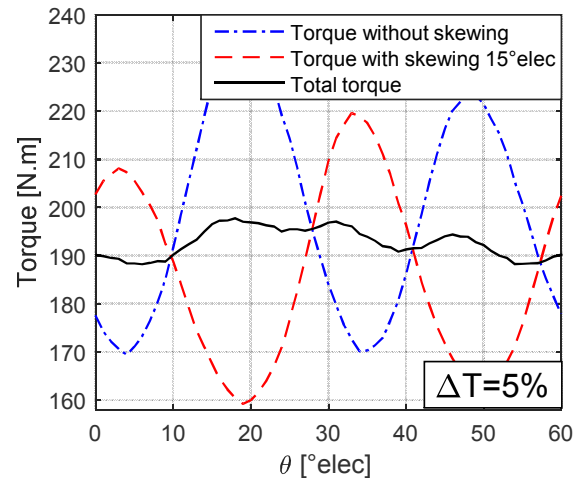

Fig. 18. Total torque ripple with a skew angle of $15^{\circ} \mathrm{elec}$

\section{Asymmetric Pole torque ripple reduction}

When designing the rotor of an electric motor, the torque ripple is reduced by using asymmetric poles. Fig. 4 denotes that the two main parameters of a barrier are the tilt angle $\delta$ and the ratio of the barrier's opening angle $k$.

\section{1) Effect of the parameter $\delta$}

A series of simulations are performed with different values of $\delta$ while maintaining the same values of $k$ and the same PM volume. The current angle is set to $30^{\circ} \mathrm{elec}$. The results shown in Fig. 19 imply that varying $\delta$ between 0 and $15^{\circ}$ keeps $\Delta T$ between $35 \%$ and $38.5 \%$ which is practically unchanged. Thus, the parameter $\delta$ does not influence the torque ripple directly. It can then be fixed at a value of $15^{\circ}$.

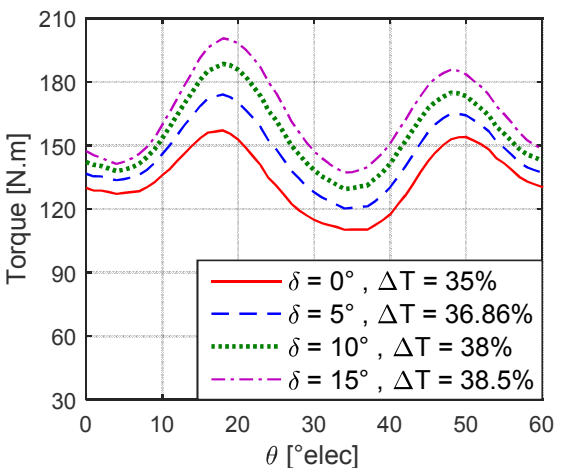

Fig. 19. Torque ripple for different values of $\delta$ at constant PM volume

\section{2) Effect of the parameter $k$}

In order to study the influence of the barrier opening angle, four variables are defined: $k_{i j}$ with $i=\{1,2\}$ and $\mathrm{j}=\{1,2\}$. The index " $i$ " corresponds to the magnetic pole type (North or South) and the index " $j$ " corresponds to the number of the barrier.

A Design of Experiments (DOE) is carried out using the predefined 4 variables: $k_{11}, k_{12}, k_{21}$ and $k_{22}$ as inputs and the average torque, the $1^{\text {st }}$ and the $2^{\text {nd }}$ harmonic as outputs. Each variable has 4 levels defined within the following ranges:

- $\quad k_{12}$ and $k_{22} \in[0.1,0.3]$

- $\quad k_{11}$ and $k_{21} \in[0.5,0.7]$

The variation limits are chosen in a way that guarantees the non-overlap of the barriers. The 4 levels of each variable are defined using the distances $[-1,-0.5,0.5,1]$ with respect to the center of each interval. For instance, the $k_{12}$ interval center is 0.2 so this variable takes the following values: $0.1,0.15,0.25$ 
and 0.3.The FEA is conducted at $40 \mathrm{~A}$ (rms) with a current angle $\alpha_{o p t}=30^{\circ}$ elec. Fig. 20, Fig. 21 and Fig. 22 show the results of the first order interaction between the inputs and the outputs.

According to Fig. 20, the highest torque value is obtained for $k_{11}=0.7$ (blue dashed line) and $k_{21}=0.7$. However, $k_{12}$ and $k_{22}$ are constant regardless of what value is set for $k_{11}$ and $k_{21}$.

In Fig. 21, for $k_{11}=0.7$, the minimum amplitude of the $1^{\text {st }}$ harmonic is given for $k_{12}=0.15, k_{21}=0.7$ and $k_{22}=0.25$. The second row suggests a minimum value for $k_{12}=0.25$ (red continuous line), but this contradicts the analysis of the first row and increases the amplitude of the $1^{\text {st }}$ harmonic. Hence, the results of the first row, marked by black squares, are chosen.

As for the $2^{\text {nd }}$ harmonic, Fig. 22 shows that for $k_{11}$ set to 0.7 , the minimum amplitude is reached for $k_{12}=0.15, k_{22}=$ 0.15 and $k_{21}=0.5$. However, setting $k_{21}$ to 0.5 decreases the average torque according to Fig. 20. A compromise is made between maximizing the average torque and minimizing the amplitude of the $2^{\text {nd }}$ harmonic, so the value of 0.65 is chosen for $k_{21}$. Black square markers are used to locate the selected values. A summary of the DOE results is given in TABLE III.

TABLE III. RESULTS OF THE DOE

\begin{tabular}{|c|c|c|c|c|c|}
\hline Objective & $\boldsymbol{k}_{\mathbf{1 1}}$ & $\boldsymbol{k}_{\mathbf{1 2}}$ & $\boldsymbol{k}_{\mathbf{2 1}}$ & $\boldsymbol{k}_{\mathbf{2 2}}$ & $\boldsymbol{\delta}$ \\
\hline Maximize the average torque & 0.7 & $\begin{array}{c}\text { No } \\
\text { impact }\end{array}$ & 0.7 & $\begin{array}{c}\text { No } \\
\text { impact }\end{array}$ & $15^{\circ}$ \\
\hline Minimize the $1^{\text {st }}$ harmonic & 0.7 & 0.15 & 0.7 & 0.25 & $15^{\circ}$ \\
\hline Minimize the $2^{\text {nd }}$ harmonic & 0.7 & 0.15 & 0.65 & 0.15 & $15^{\circ}$ \\
\hline
\end{tabular}

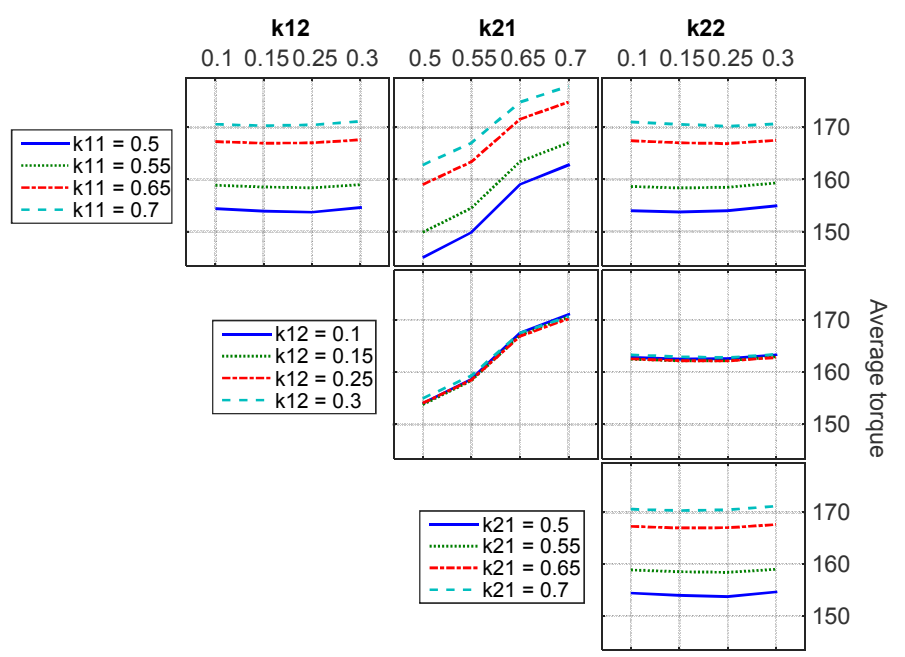

Fig. 20. Results of the DOE for the average torque

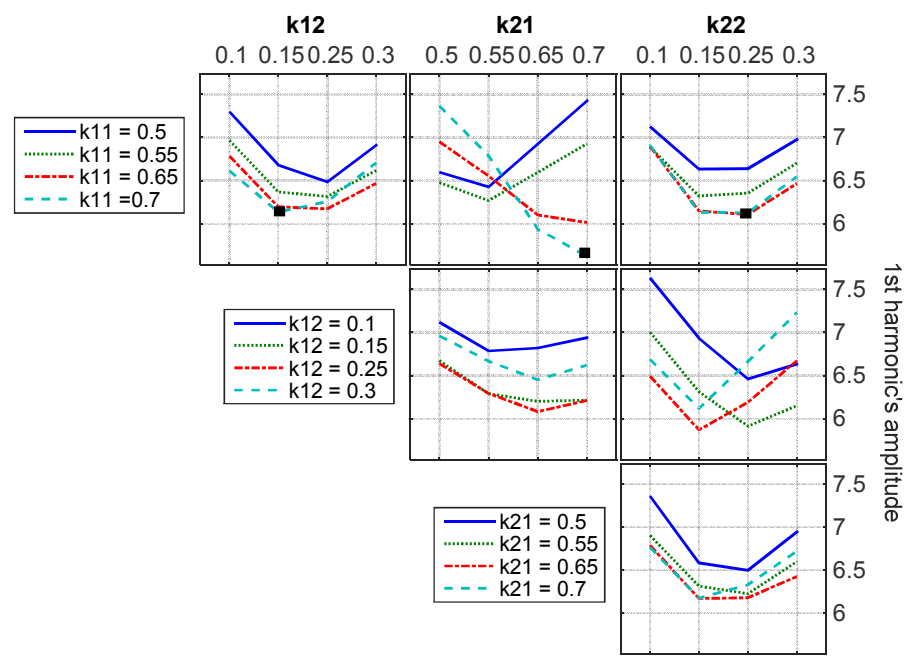

Fig. 21. Results of the DOE for the $1^{\text {st }}$ harmonic' amplitude

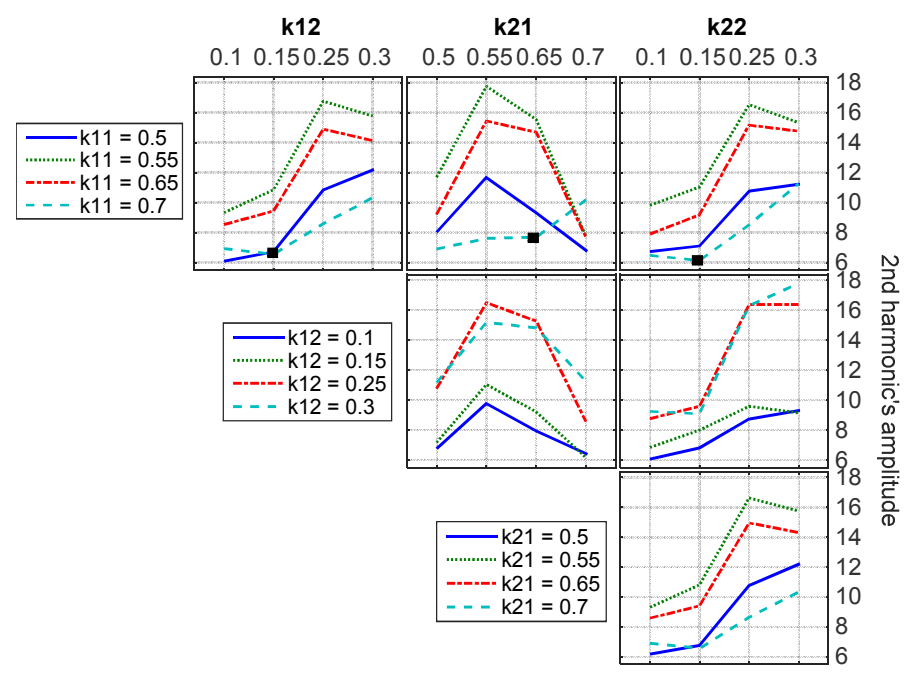

Fig. 22. Results of the DOE for the $2^{\text {nd }}$ harmonic amplitude

The configurations that minimize either the $1^{\text {st }}$ or the $2^{\text {nd }}$ harmonic lead to an asymmetric pole structure.

\section{3) Minimization of the $2^{\text {nd }}$ harmonic}

As shown in Fig. 17 the $2^{\text {nd }}$ harmonic is the dominant harmonic amplitude. The configuration that minimizes the $2^{\text {nd }}$ harmonic is tested with $k_{11}=0.7, k_{21}=0.65$ and $k_{12}=k_{22}=$ 0.15 . The torque ripple and its harmonic decomposition are presented in Fig. 23 and Fig. 24. $\Delta T$ passes from 33\% to 8.2\%. The $2^{\text {nd }}$ harmonic is reduced significantly. However, the first harmonic remains relatively high and is responsible for the remaining torque ripple. To further reduce the torque ripple different strategies to combine the step skew and the asymmetric poles are investigated.

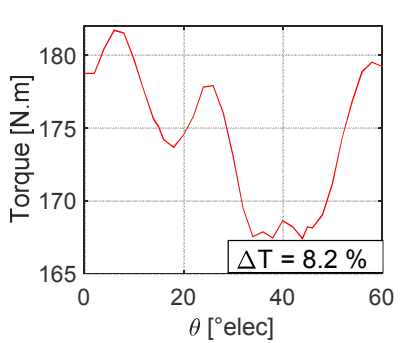

Fig. 23. Torque ripple with the 2 nd harmonic reduced using asymmetric poles

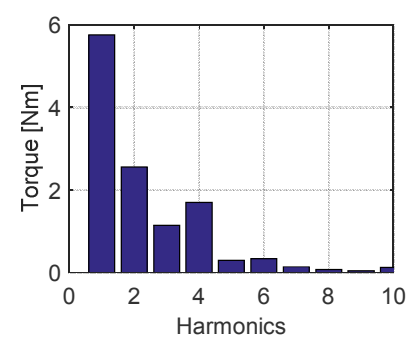

Fig. 24. FFT of the torque with the 2nd harmonic reduced using asymmetric poles

\section{E. Combination of Rotor Step Skewing and Asymmetric Poles}

1) $1^{\text {st }}$ strategy: Reduction of the $2^{\text {nd }}$ harmonic using asymmetric poles and the $1^{\text {st }}$ harmonic by rotor step skewing

The minimization of the $2^{\text {nd }}$ harmonic using asymmetric poles leads to $\Delta T=8.2 \%$. The rotor step skew is used to reduce the $1^{\text {st }}$ harmonic which now becomes the largest (Fig. 24). Since its period is $60^{\circ} \mathrm{elec}$, a phase shift of $180^{\circ} \mathrm{elec}$ is obtained with:

$$
\psi_{\text {skew }}=60 \frac{180}{360}=30^{\circ} \text { elec }=6^{\circ} \mathrm{meca}
$$

$\Delta T$ decreases from $8.2 \%$ to $6 \%$ as shown in Fig. 25 . The torque ripple reduction is not significant because of the high skew angle. In fact, skewing the rotor is equivalent to increasing the current angle. Adding $30^{\circ}$ elec to $\alpha_{o p t}=30^{\circ}$ elec leads to a current angle of $60^{\circ} \mathrm{elec}$ which significantly decreases $T_{\text {avg, }}$, it 
passes from $200 \mathrm{Nm}$ to $145 \mathrm{Nm}$ according to Fig. 14. Thus, the ratio given by Eq. 3 does not improve much.

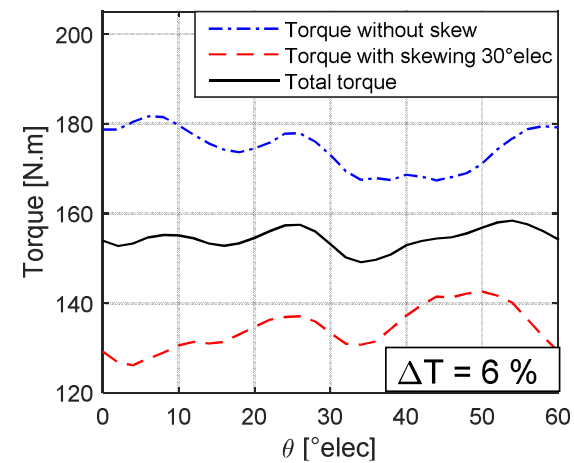

Fig. 25. Total torque ripple using the 1st strategy

2) $2^{\text {nd }}$ strategy: Reduction of the $1^{\text {st }}$ harmonic by asymmetric poles and the $2^{\text {nd }}$ harmonic by rotor step skewing

Based on the previous analysis, another strategy is proposed. The $1^{\text {st }}$ harmonic is reduced using asymmetric poles (TABLE III) and leads to $\Delta T=11.63 \%$. The structure is then step skewed in order to reduce the $2^{\text {nd }}$ harmonic with $\psi_{\text {skew }}=$ $15^{\circ}$ elec $=3^{\circ} \mathrm{meca}$.

The result given in Fig. 26 shows that $\Delta T=4.62 \%$. Skewing the rotor by $15^{\circ}$ elec does not decrease $T_{\text {avg }}$ significantly; it passes from $200 \mathrm{Nm}$ to $187 \mathrm{Nm}$ according to Fig. 14. Hence, the ratio given in Eq.3 is reduced.

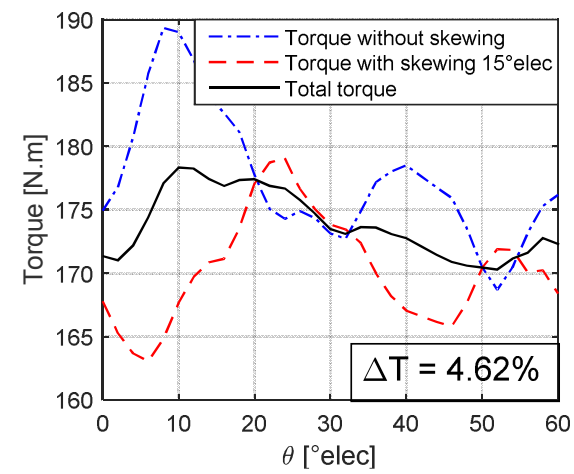

Fig. 26. Total torque ripple using the 2nd strategy

\section{3) Improved $2^{\text {nd }}$ strategy}

As mentioned previously, the barrier tilt angle $\delta$ does not affect the torque ripple directly. However, reducing $\delta$ results in increasing the PM volume so that $T_{a v g}$ is increased and the ratio (Eq.3) further decreases. The result of the $2^{\text {nd }}$ strategy with $\delta=5^{\circ}$ is shown in Fig. 27. The following table summarizes the results for different values of $\delta$.

TABLE IV. TORQUE RIPPLE USING THE $2^{\text {ND }}$ STRATEGY WITH DIFFERENT VALUES OF $\delta$

\begin{tabular}{|c|c|c|c|}
\hline $\boldsymbol{\delta}\left[{ }^{\circ}\right]$ & $\boldsymbol{T}_{\boldsymbol{p} \boldsymbol{}}[\mathbf{N m}]$ & $\boldsymbol{T}_{\boldsymbol{a v g}}[\mathbf{N m}]$ & $\boldsymbol{\Delta T}[\boldsymbol{\%}]$ \\
\hline 15 & 8 & 174 & 4,6 \\
\hline 10 & 7,1 & 183 & 3,8 \\
\hline 7,5 & 6,92 & 189,6 & 3,65 \\
\hline 5 & 6,7 & 196 & 3,44 \\
\hline
\end{tabular}

Changing the value of $\delta$ does not significantly affect the peakto-peak value of the torque but increases its average value so the torque ripple is further reduced.

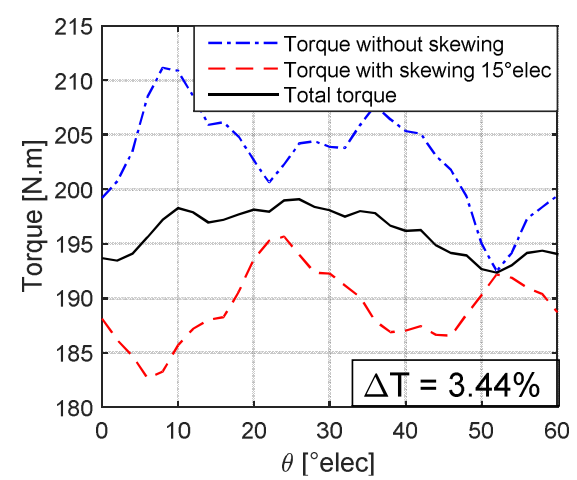

Fig. 27. Total torque ripple using the 2 nd strategy with $\delta=5^{\circ}$

\section{F. Conclusions on the $12 / 10$ structure}

The performance of the $12 / 10$ motor has been investigated. This structure is able to produce a high torque at low speed with an acceptable power factor. The main drawback of this configuration is the high torque ripple that it exhibits. However, the torque quality can be improved using rotor step skew but the average torque is decreased. As for the asymmetric rotor pole technique, it reduces the torque ripple but not below the target value of 5\%. Different combinations of the above techniques are investigated. In this paper, the proposed strategy for the $12 / 10$ motor reduces the $1^{\text {st }}$ harmonic using asymmetric poles and the $2^{\text {nd }}$ harmonic using rotor step skew with a low value of the barrier tilt angle. This combination reduces the torque ripple significantly without significantly reducing the average torque.

\section{COMPARISON OF THE 18/16 AND THE 12/10 STRUCTURES}

In terms of torque and power factor, both structures achieve a high average torque at low speed with a power factor of around 0.7. Since the two motors are doubly-salient structures, their optimal current angle is low and is equivalent to a low saliency torque. The $12 / 10$ motor develops the highest torque at $\alpha_{o p t}=30^{\circ}$ (Fig. 14). As for the 18/16 motor, it has the highest torque for $\alpha_{\text {opt }}=20^{\circ}$ and cannot attain an optimal current angle of $30^{\circ}$ without reducing the average torque (Fig.10).

The last comparison criterion is the quality of the torque. The 18/16 motor does not require further modifications in the structure to obtain low torque ripple since it develops a smooth torque. On the contrary, the 12/10 motor suffers from high torque ripple that can be reduced by using a combination of techniques but this may complicate the improved structure. The following table summarizes the main comparison points:

TABLE V. COMPARISON SUMMARY

\begin{tabular}{|c|c|c|}
\cline { 2 - 3 } \multicolumn{1}{c|}{} & $\mathbf{1 8 / 1 6}$ motor & $\mathbf{1 2 / 1 0}$ motor \\
\hline Average torque & Good & Good \\
\hline Power factor & Good & Good \\
\hline Machine saliency & Very bad & Bad \\
\hline Torque ripple & Very good & Very bad \\
\hline
\end{tabular}

The choice of structure that is more suitable for a high torque and low speed application depends whether the target is to design a motor that is relatively easy to manufacture, with satisfactory performances, or to minimize the PM volume despite the modifications made to the structure to obtain the desired performance.

Since the cost of ferrite magnets is low; one may favor the less complex structure. Thus, the $18 / 16$ motor would be an appropriate choice and may be the subject of future work. 


\section{CONCLUSION}

In this paper a novel doubly salient structure with concentrated tooth winding and multi- $\mathrm{V}$ shape ferrite magnets is studied. Two slot/pole combinations are investigated: the $18 / 16$ and the 12/10. The performance of each machine is analyzed using 2D Finite Element Analysis (FEA). Both motors exhibit a high torque at low speed with a good power factor. The 18/16 develops a smooth torque without implementing any torque ripple reduction technique. On the other hand, the 12/10 structure can overcome its high torque ripple using appropriate rotor electromagnetic design.

A DOE is carried out and the analysis of the results leads to asymmetric pole configurations that can reduce specific torque harmonics. In addition, a combination of rotor step skew and the asymmetric pole technique is proposed for the 12/10 machine and leads to a torque ripple of $3.44 \%$ without significantly reducing the average torque.

Finally, the comparison of both motors shows their suitability for high torque and low speed applications. A compromise has to be made between the permanent magnet additional cost in the case of $18 / 16$ machine and the rotor manufacturing complexity in case of the $12 / 10$ machine.

\section{REFERENCES}

[1] Y. Wang, M. Cheng, M. Chen, Y. Du, and K. T. Chau, "Design of high-torque-density double-stator permanent magnet brushless motors," IET Electric Power Applications, vol. 5, no. 3, pp. 317-323, Mar. 2011.

[2] F. Zhao, T. A. Lipo, and B. Kwon, "Dual-stator Interior Permanent Magnet Vernier Machine Having Torque Density and Power Factor Improvement," Electric Power Components and Systems, vol. 42, no. 15, pp. 1717-1726, Nov. 2014.

[3] Y. A. Alamoudi, G. A. Atkinson, and B. Mecrow, "A split tooth permanent magnet machine design for high torque applications," in 2014 International Conference on Electrical Machines (ICEM), 2014, pp. 360-367.

[4] K. Sato, R. Hosoya, and S. Shimomura, "Improved ferrite magnet vernier machine for an in-wheel machine," in IEEE International Conference on Power and Energy (PECon), 2012, pp. 414-419.

[5] S. L. Ho, S. Niu, and W. N. Fu, "Design and Comparison of Vernier Permanent Magnet Machines," IEEE Transactions on Magnetics, vol. 47, no. 10, pp. 3280-3283, Oct. 2011.

[6] Y. Fan, L. Gu, Y. Luo, X. Han, M. Cheng, Y. Fan, L. Gu, Y. Luo, X. Han, and M. Cheng, "Investigation of a New Flux-Modulated Permanent Magnet Brushless Motor for EVs, Investigation of a New Flux-Modulated Permanent Magnet Brushless Motor for EVs," The Scientific World Journal, The Scientific World Journal, vol. 2014, 2014, p. e540797, Apr. 2014.

[7] A. Zulu, B. C. Mecrow, and M. Armstrong, "Permanent-Magnet FluxSwitching Synchronous Motor Employing a Segmental Rotor," IEEE Transactions on Industry Applications, vol. 48, no. 6, pp. 2259-2267, Nov. 2012.

[8] A. Gandhi and L. Parsa, "Double-rotor flux-switching machine," US Patent 20140049124 A1.

[9] Y. J. Zhou and Z. Q. Zhu, "Torque Density and Magnet Usage Efficiency Enhancement of Sandwiched Switched Flux Permanent Magnet Machines Using V-Shaped Magnets," IEEE Transactions on Magnetics, vol. 49, no. 7, pp. 3834-3837, Jul. 2013.

[10] Z. Q. Zhu, J. T. Chen, Y. Pang, D. Howe, S. Iwasaki, and R. Deodhar, "Analysis of a Novel Multi-Tooth Flux-Switching PM Brushless AC Machine for High Torque Direct-Drive Applications," IEEE Transactions on Magnetics, vol. 44, no. 11, pp. 4313-4316, Nov. 2008.

[11] E. Sulaiman, T. Kosaka, N. Matsui, and M. Z. Ahmad, "Design studies on high torque and high power density hybrid excitation flux switching synchronous motor for HEV applications," in Power Engineering and Optimization Conference (PEDCO) Melaka, Malaysia, 2012 Ieee International, 2012, pp. 333-338.
[12] D. Wu, X. Liu, Z. Q. Zhu, A. Pride, R. Deodhar, and T. Sasaki, "Novel switched flux hybrid magnet memory motor," in 7th IET International Conference on Power Electronics, Machines and Drives (PEMD 2014), 2014, pp. 1-6.

[13] M. Z. Ahmad, E. Sulaiman, Z. A. Haron, and T. Kosaka, "Design improvement of a new outer-rotor hybrid excitation flux switching motor for in-wheel drive EV," in Power Engineering and Optimization Conference (PEOCO), IEEE 7th International, 2013, pp. 298-303.

[14] W. Hua, M. Cheng, and G. Zhang, "A Novel Hybrid Excitation FluxSwitching Motor for Hybrid Vehicles," IEEE Transactions on Magnetics, vol. 45, no. 10, pp. 4728-4731, Oct. 2009.

[15] H. Torkaman, E. Afjei, A. Gorgani, N. Faraji, H. Karim, and N. Arbab, "External rotor SRM with high torque per volume: design, analysis, and experiments," Electr Eng, vol. 95, no. 4, pp. 393-401, Nov. 2012.

[16] M.-J. Kim, S.-Y. Cho, K.-D. Lee, J.-J. Lee, J.-H. Han, T.-C. Jeong, W.-H. Kim, D. Koo, and J. Lee, "Torque Density Elevation in Concentrated Winding Interior PM Synchronous Motor With Minimized Magnet Volume," IEEE Transactions on Magnetics, vol. 49, no. 7, pp. 3334-3337, Jul. 2013.

[17] S.-I. Kim, S. Park, T. Park, J. Cho, W. Kim, and S. Lim, "Investigation and Experimental Verification of a Novel Spoke-Type Ferrite-Magnet Motor for Electric-Vehicle Traction Drive Applications," IEEE Transactions on Industrial Electronics, vol. 61, no. 10 , pp. 5763-5770, Oct. 2014.

[18] S. Morimoto, S. Ooi, Y. Inoue, and M. Sanada, "Experimental Evaluation of a Rare-Earth-Free PMASynRM With Ferrite Magnets for Automotive Applications," IEEE Transactions on Industrial Electronics, vol. 61, no. 10, pp. 5749-5756, Oct. 2014.

[19] D. Prieto, B. Daguse, P. Dessante, P. Vidal, and J. Vannier, "Effect of magnets on average torque and power factor of Synchronous Reluctance Motors," in 2012 XXth International Conference on Electrical Machines (ICEM), 2012, pp. 213-219.

[20] Y. Kano, "Torque Ripple Reduction of Saliency-Based Sensorless Drive Concentrated-Winding IPMSM Using Novel Flux Barrier," IEEE Transactions on Industry Applications, vol. 51, no. 4, pp. 2905 2916, Jul. 2015.

[21] F. Meier, "Permanent-Magnet SynchronousMachines with NonOverlappingConcentrated Windings for Low-Speed Direct-Drive Applications," Royal Institute of Technology School of Electrical Engineering Electrical Machines and Power Electronics, Stockholm, 2008

[22] G. Verez, G. Barakat, Y. Amara, O. Bennouna, and G. Hoblos, "Impact of pole and slot combination on noise and vibrations of fluxswitching PM machines," in International Conference on Electrical Machines (ICEM), 2014, pp. 182-188.

[23] T. M. Jahns and W. L. Soong, "Pulsating torque minimization techniques for permanent magnet AC motor drives-a review," IEEE Transactions on Industrial Electronics, vol. 43, no. 2, pp. 321-330, Apr. 1996.

[24] R. P. Deodhar, D. A. Staton, and T. J. E. Miller, "Modeling of skew using the flux-MMF diagram," IEEE Transactions on Industry Applications, vol. 32, no. 6, pp. 1339-1347, Nov. 1996.

[25] W. Q. Chu and Z. Q. Zhu, "Reduction of On-Load Torque Ripples in Permanent Magnet Synchronous Machines by Improved Skewing," IEEE Transactions on Magnetics, vol. 49, no. 7, pp. 3822-3825, Jul. 2013.

[26] J. Richnow, D. Gerling, and P. Stenzel, "Torque ripple reduction in permanent magnet synchronous machines with concentrated windings and pre-wound coils," in 17th International Conference on Electrical Machines and Systems (ICEMS), 2014, pp. 2501-2507.

[27] Y. Li, D. Bobba, and B. Sarlioglu, "A Novel Dual-Stator Flux Switching Permanent Magnet Machinewith Six Stator Slots and Four Rotor Poles Configuration," in IEEE International Electric Machines and Drives Conference (IEMDC), 2015, pp. 1566-1572.

[28] M. Sanada, K. Hiramoto, S. Morimoto, and Y. Takeda, "Torque ripple improvement for synchronous reluctance motor using an asymmetric flux barrier arrangement," IEEE Transactions on Industry Applications, vol. 40, no. 4, pp. 1076-1082, Jul. 2004.

[29] T. Lange, B. Kerdsup, C. Weiss, and R. W. De Doncker, "Torque ripple reduction in Reluctance Synchronous Machines using an asymmetric rotor structure," in 7th IET International Conference on Power Electronics, Machines and Drives (PEMD), 2014, pp. 1-5.

[30] A. Pina and L. Xu, "Modeling of Synchronous Reluctance Motors Aidedby Permanent Magnets with Asymmetric RotorPoles," in IEEE International Electric Machines and Drives Conference (IEMDC), 2015, pp. 412-418. 